\title{
Visión personalista de K. Wojtyla del acto conyugal
}

Dr. José M. ${ }^{a}$ Mora MonTes

Neuropsiquiatra

Sinopsis: Este trabajo gira en torno a la visión personalista del acto conyugal de Wojtyla (san Juan Pablo II), que acomodó a su labor catequística durante los 26 años de su pontificado. Las conclusiones a las que llegó en el aspecto moral están en concordancia con la doctrina secular de la Iglesia Católica, pero en otras cuestiones se abre a notables innovaciones. La importancia concedida al acto conyugal elevado al nivel de las manifestaciones espirituales de la personalidad y el incardinar el amor en la sexualidad son algunas de las cuestiones debatidas. Esta nueva doctrina sobre la sexualidad conyugal que surge del Concilio Vaticano II es confrontada con los conocimientos médicos y psicológicos actuales. El resultado es una clara divergencia con lo establecido por la Ciencia y también con lo aceptado por la teología católica anterior al Concilio, de forma muy especial en lo referente a los fines del matrimonio.

Palabras clave: Juan Pablo II. Personalismo. Acto conyugal. Fines del matrimonio.

Synopsis: This work revolves around the personalistic vision of the conjugal act of Wojtyla (Saint John Paul II), which accommodated his catechetical work during the 26 years of his pontificate. The conclusions reached in the moral aspect are in accordance with the secular doctrine of the Catholic Church, but in other matters it opens up to notable innovations. The importance given to the conjugal act raised to the level of the spiri- 
tual manifestations of the personality, or to incardinate love in sexuality are some of the issues debated. This new doctrine on conjugal sexuality is confronted with current medical and psychological knowledge. The result is a clear divergence with what is established by Science and also with what is accepted by Catholic theology prior to the Council, in a very special way with regard to the purposes of marriage.

Keywords: John Paul II. Personalism. Conjugal act. Purpose of marriage.

\section{Introducción}

La sexualidad humana es compleja, muy amplia en contenidos, y quedan aún muchos aspectos que no han sido debidamente estudiados. Sus manifestaciones no han de ser reducidas a la genitalidad al ser esta tan solo una parte de un campo muchísimo más amplio, pero, precisamente en la genitalidad es donde la ciencia ha puesto el interés y ha volcado las investigaciones. Otros muchos aspectos se han despreciado, quizás por pensar que su interés pertenece a la literatura, filosofía y teología, pero no a la ciencia.

Karol Wojtyla reflexionó sobre la sexualidad humana y especialmente sobre el acto conyugal desde una perspectiva filosófica personalista, dentro de una serie de postulados que en su conjunto denominó "teología del cuerpo". Al contemplar sus contenidos es difícil no preguntarse si los principios que sustentan su doctrina concuerdan o no con los que sostienen otras ciencias del hombre. No se trata de comprobar la coincidencia entre Ciencia y Fe, porque los principios del papa polaco no constituyen dogmas, ni verdades de fe, ni siquiera se ajustan a la doctrina tradicional de la Iglesia Católica, ni se ajustan a otros criterios filosóficos y teológicos no personalistas. En este artículo simplemente, se analizan y cuestionan aspectos de la sexualidad humana, centrados especialmente en el acto sexual matrimonial que Karol Wojtyla mantuvo a lo largo de su vida, e inicialmente enseñó como profesor de Ética de la universidad de Lublín.

Se tienen en cuenta dos libros de gran divulgación de Juan Pablo II (JP II), además de la encíclica Familiaris Consortio (FC), que son: Amor y responsabilidad. Estudio de moral sexual (1969) y Varón y mujer. Teología del cuerpo (1996). El primer libro, escrito en polaco, se publicó en Lublín 1960 y dos años después, con más volumen y algunas modificaciones, 
se publicó en Cracovia. La versión citada es de 1969, procedente de una edición francesa. En su contenido se mezclan nociones psicológicas, teológicas y sobre todo aportaciones personalistas, fruto de sus reflexiones sobre los temas de la familia y el acto conyugal. El segundo libro es de índole más teológica y desarrolla la creación del hombre (varón y mujer) según el Génesis, a imagen y semejanza de Dios, no solo en cuanto la masculinidad y la feminidad, constituyen una unidad, sino también en cuanto hombre y mujer constituyen una "comunión" de personas.

Wojtyla, siendo arzobispo de Cracovia colaboró sustancialmente en la redacción de la constitución pastoral Gaudium et Spes (GS), uno de los más importantes documentos del Concilio Vaticano II, que incluye temas relacionados con el matrimonio y la familia, firmada por Pablo VI el 7 de diciembre de 1965. En esta Constitución es fácil descubrir la impronta de Wojtyla en muchos conceptos que son similares o idénticos a los que empleará después en muchas catequesis y escritos, especialmente en su libro Varón y mujer, teología del cuerpo. Sea como fuere, en esta Constitución hay varios conceptos merecedores de atención, como propios de Wojtyla, que serán comentados. Una vez proclamado Papa en 1979, con el nombre de Juan Pablo II, vivirá 26 años, y su pontificado, el tercero más largo de la historia de la Iglesia Católica, le permitirá divulgar y afianzar sus enseñanzas pastorales. Por otra parte, los estudios realizados por laicos y sacerdotes en los Institutos Pontificios Juan Pablo II, donde se enseña la "Teología del cuerpo", han sido de capital importancia para que esta doctrina tenga una proyección internacional, con entusiastas seguidores que la han divulgado ampliamente en los círculos sociales católicos.

Dada la amplitud de temas contenidos en la teología del cuerpo, este artículo se centra exclusivamente en la premisa de que el acto sexual es una expresión de amor entre los cónyuges, marido y mujer. Sobre esta base, de inspiración personalista, se desprenden otras ideas y derivaciones que serán igualmente valoradas.

\section{EL ACTO SEXUAL ES UNA EXPRESIÓN DE AMOR}

\subsection{Donación de sí mutua y recíproca}

Wojtyla antes de ser Papa se mostró muy interesado por los problemas del matrimonio y la familia. En sus obras es patente el influjo de la filosofía 
personalista, auspiciada por el pensador católico francés Emmanuel Mounier (1905-1950), Max Scheler (1874-1928) y Dietrich von Hildebrand (1889-1977), entre otros, que enfatiza la dignidad humana y resalta el papel de la libertad, la afectividad y muy especialmente el amor, constitutivos de la dimensión central de la personalidad. Es una filosofía moderna, de índole subjetivista derivada del "cogito ergo sum" de Descartes.

Quiso Wojtyla junto con otras figuras destacadas del Concilio Vaticano II (CV II) una renovación de la Iglesia y modificar posiciones pastorales que se habían mantenido secularmente, de ahí que con voluntad reformadora afirmará, en Amor y responsabilidad, que la teología católica ha mantenido una visión negativa de la sexualidad y solo ve una "tea" de pecado ${ }^{1}$, es decir, ocasiones de pecar. La visión negativa de la sexualidad era preciso cambiarla por otra positiva donde se contemplara la belleza de la unión conyugal dignificada por el afecto y así la sexualidad podría curarse de ese supuesto veneno que, según Nietzsche, el cristianismo hizo beber a Eros.

Wojtyla, refiriéndose a la vida matrimonial juzgó que el hombre y la mujer en su unión física sexual están capacitados para "darse" mutuamente en la totalidad del amor, con toda la potencialidad de la masculinidad y de la feminidad. Él quiso decir que se "unen" para expresar su amor, de igual forma que una madre abraza al hijo y mediante ese apretón le muestra su cariño. Asumió totalmente cuanto se dice en Gaudium et Spes (GS), muy posiblemente dictados algunos capítulos por él mismo, donde se puede leer:

Que el amor de los esposos se expresa y perfecciona singularmente con la acción propia del matrimonio. Por ello los actos con los que los esposos se unen íntima y castamente entre sí son honestos y dignos, y, ejecutados de manera verdaderamente humana, significan y favorecen el don recíproco, con el que se enriquecen mutuamente en un clima de gozosa gratitud (GS 49).

Nos encontramos con unos párrafos de denso contenido que Wojtyla aceptó en su totalidad y que desarrollará en años sucesivos. Siendo Papa, en la encíclica Familiaris consortio (FC, 11) afirmó: "la sexualidad, mediante la cual el hombre y la mujer se dan uno a otro con los actos propios

${ }^{1}$ Wojtyla, K, Amor y responsabilidad. Estudio de moral sexual, Madrid, Razón y Fe, 1979, p. 177. 
y exclusivos de los esposos" (FC 11) y en Varón y mujer. Teología del сиегро:

La capacidad de expresar el amor: ese amor precisamente en el que el hombre-persona se convierte en don y-mediante este don- realiza el sentido mismo de su ser y existir (...) este significado (esponsalicio) indica una capacidad particular de expresar el amor, en el que el hombre se convierte en don².

Para el Papa esta donación entre esposos expresa su mutuo amor. Por eso en la misma encíclica declaró: "el amor es esencialmente don" (FC 14). Afirmar que los esposos en el acto matrimonial "se dan", tiene una connotación bien querida del Papa que usa de ella para afirmar que tales actos son manifestación de amor. Hay una notable insistencia y constituye una idea básica de su doctrina que el acto matrimonial es una expresión de amor; una idea expuesta con toda claridad. Si hubiera afirmado que la actividad sexual es concebida "como" la expresión del amor entre los cónyuges dado en exclusividad y reciprocidad, el significado sería distinto, pues el "como" permitiría interpretar que la actividad sexual representa, es imagen, icono, simboliza, alude, con las que no cabe confusión y se asumen sin dificultad. También la expresión "darse" de Wojtyla podría interpretarse como el hecho de unirse los esposos sin más en la cópula, de forma similar a decir que cada uno participa, interviene, contribuye en la realización del acto. Pero no hay lugar a equívocos porque JP II reitera que mediante la donación de sí, mutua y recíproca, los esposos dicen cuánto se aman. En la carta Gratisimam Sane reafirma ideas previamente expuestas en otros documentos: "El acto conyugal es de donación mutua; sin duda alguna de signo amoroso: Los esposos desean los hijos para sí, y en ellos ven la coronación de su amor recíproco"3.

El concepto de "significado unitivo" del acto sexual, que el papa polaco divulgó, va más allá de lo que a simple vista se piensa, pues expresa una donación plena, total, expresión de un gran amor que ha de incluir el potencial de la paternidad y la maternidad inherentes a la persona humana. El hombre no solo se entrega en la totalidad de su ser sino que

2 JuAn Pablo II, Varón y mujer. Teología del cuerpo, Madrid, Ed. Palabra, 1996, p. 107-8.

3 JUAn PABlo II, “Carta Gratisimam Sane”, 9, Libreria Editrice Vaticana, 1994. 
ofrece sus espermatozoides (sus semillas) a la mujer, que a su vez le ofrece en reciprocidad sus óvulos. No solo los esposos experimentan el sentimiento amoroso, sino que también sus cuerpos deben manifestarlo. De esta forma la idea del coito como "expresión de amor" en alma y cuerpo queda reforzada, sin posibilidad de nada mayor.

\subsection{Juan Pablo II y los fines del matrimonio}

En su línea de rigurosa fidelidad al Concilio, JP II modificó los "fines tradicionales del matrimonio" establecidos en el Derecho Canónico, vigentes desde Tomás de Aquino (1225-1274), y entró de esta forma en el secular problema de los fines del matrimonio, aunque el vocablo "fines" se evitó después del Concilio, que quiso renovar la Iglesia con una terminología diferente. Es interesante este cambio por lo inusual, pues rara ha sido la civilización que no ha considerado como un fin principal del matrimonio la procreación. Así, por ejemplo, ocurría en la Grecia antigua, cuando con el nacimiento de los hijos, especialmente si eran varones, se aseguraba el mantenimiento del culto familiar. Lo mismo ocurría en Roma, tanto así que el vocablo "matrimonio" proviene del latín "matrimonium" y esta voz, en su origen, se encontraba formada por las raíces latinas matr-, procedente del vocablo latino mater, matris, que significa "madre", y por el elemento -monium, que se empleaba para designar los actos propios de la madre.

El cristianismo fue en cierto modo continuador de la tradición judaica y estableció los sacramentos del Matrimonio para las parejas que se unían para formar familia y del Bautismo para sus hijos. Desde santo Tomás (s. XIII) la Iglesia Católica aceptó la existencia de fines esenciales que pertenecen propiamente al matrimonio y fines accidentales que son aquellos que no siempre se manifiestan, y pueden faltar. En los fines primarios incluía la procreación y educación de los hijos y en los secundarios, estaría en primer lugar la ayuda mutua, y luego, el "remedium concupiscenciae". Distinguir los fines primarios de los secundarios era importante, pues suponía, como bien afirma Cristian Conen ${ }^{4}$ una subordinación en orden de importancia de los segundos a los primeros. El canon 1013,1 del Código de

${ }^{4}$ Conen, C. "El fin matrimonial del bonum coniugum en el pensamiento de Karol Wojtyla / Juan Pablo II”, Franciscanum, nº 167, Vol. LIX (2017): 319-350. 
1917 decía exactamente: "La procreación y la educación de la prole es el fin primario del matrimonio; la ayuda mutua y el remedio de la concupiscencia es su fin secundario". Pues bien, el nuevo Código de Derecho Canónico, modificado y promulgado por JP II en 1983, estableció:

La alianza matrimonial, por la que el varón y la mujer constituyen entre sí un consorcio de toda la vida, ordenado por su misma índole natural al bien de los cónyuges y a la generación y educación de la prole, fue elevada por Cristo Señor a la dignidad de sacramento entre bautizados (canon 1055,1).

Desde entonces ha de entenderse que el matrimonio tiene como fin ("está ordenado") al bien de los cónyuges y a la generación y educación de la prole. Esta es la gran novedad que surge en el postconcilio (pontificado de JP II): el "bien de los cónyuges" se incorpora como fin y queda igualado en importancia con la procreación. El "bien de los cónyuges" forma parte de una nueva visión del matrimonio, no idéntica a la precedente. ¿Y cuál es el "bien de los cónyuges"? Pues el amor que une a los esposos y todo aquello que los lleva a una vida de perfección como padres y como cónyuges. El Papa sostuvo que el amor y la procreación están nivelados en importancia en el matrimonio y puesto que los actos sexuales incrementan el amor -"este amor se expresa y perfecciona singularmente con la acción propia del matrimonio"- (GS 49) tales actos han de ser, de forma muy especial, los que desarrollen la doble finalidad del matrimonio. Es más, el significado procreativo se presenta como efecto del significado unitivo. Un hombre y una mujer se unen en matrimonio para consumar su amor y de esta consumación podrá surgir una nueva vida. La apertura al hijo se presenta como consecuencia de la apertura y entrega al otro cónyuge.

La Iglesia ha enseñado desde siempre la distinción entre los dos fines, su jerarquización y la subordinación del secundario al primario. El matrimonio, como institución natural, no tiene como fin primario e íntimo el perfeccionamiento personal de los esposos, sino la procreación y la educación de la nueva vida. Por eso Pío XII decía en su alocución a las matronas:

ahora bien, a los cónyuges que hacen uso de él (del matrimonio) con el acto específico de su estado, la Naturaleza y el Creador les imponen la función de proveer a la conservación del género humano. Esta es 
la prestación característica que constituye el valor propio de su estado, el bonum prolis 5 .

Las consecuencias de la nueva doctrina conciliar fueron graves. La nivelación y desjerarquización de los fines del matrimonio permitió a muchos obispos cambiar la enseñanza de la Iglesia. En efecto, si el perfeccionamiento de los esposos y la transmisión de la vida son dos fines igualmente importantes, puede aparecer el llamado "conflicto de deberes" y se puede recurrir de manera indiscriminada a la anticoncepción.

\section{CONSIDERACIONES}

\section{1. ¿El acto sexual es una expresión de amor?}

No debe ignorarse, valga la perogrullada, que el coito es un acto de naturaleza sexual, por lo que en su consideración se ha de tener en cuenta ante todo lo que la Psicología, la Sexología y la Medicina enseñan. Hemos de partir de esta base para un mejor conocimiento del tema. Interesa una valoración del coito más objetiva y de acuerdo con la realidad. La Sexología, especialmente, tiene muy bien estudiados estos actos, pues son múltiples las parejas, que, al padecer disfunciones sexuales, desde mediados del pasado siglo acuden a clínicas para remediar falta de "deseo", miedos, represiones neuróticas, impotencias, vaginismos, y otras perturbaciones.

De esta confrontación entre la Ciencia y la Filosofía Personalista se puede argüir que la primera tiene una visión parcial al contemplar sobre todo los aspectos somato-biológicos de la sexualidad y prescindir con frecuencia de los psíquicos y espirituales. Lo cual es cierto, como también lo es que el Personalismo ignora realidades básicas de la sexualidad tales como la fuerza libidinosa que impulsa al hombre y a la mujer a fundirse en el ayuntamiento carnal.

${ }^{5}$ Pío XII, "Discurso del Santo Padre al congreso de la unión católica italiana de obstétricas con la colaboración de la federación nacional de colegios de comadronas católicas". 29 de octubre de 1951. Libreria Editrice Vaticana. 
a) Para responder a la cuestión planteada es preciso en primer lugar atender a la terminología empleada por el papa eslavo, que precisa de cuidadosa atención:

- La expresión, tantas veces repetida, el hombre y la mujer "se dan" mutuamente en el acto sexual no puede ser interpretada literalmente, porque ningún hombre se posee a sí mismo, no es dueño de su persona, ni dispone de capacidad para darse.

- Afirmaba Wojtyla, usando un lenguaje hiperbólico, que amar al otro cónyuge significa entregarle su ser, su "recíproca pertenencia", es decir, mucho más de lo que fijó Aristóteles en su Retórica. Empleó la expresión "darse" para indicar una clase de amor que supera al amor de amistad y al amor más desinteresado posible. Los juristas que han de contar con la claridad y concisión necesarias para no errar en los fallos judiciales (tal puede ocurrir cuando han de sentenciar en los casos de nulidad matrimonial), han encontrado también un escollo en la terminología del papa eslavo. En este sentido, la canonista Rocío López González asume las palabras del cardenal español Urbano Navarrete (1920-2010) cuando afirma:

La proposición «los cónyuges se dan y reciben mutuamente», se puede aceptar solo si se refiere a una donación-aceptación específica, ya que repugna a la autonomía y dignidad de la persona humana ser objeto de una donación en cuanto tal. La donación de la propia persona hace referencia necesariamente solo a la actividad de la persona, pero no a la persona misma ${ }^{6}$.

Efectivamente, el Papa alude a la donación específica de los gametos que se ha de producir en el acto sexual para que sea moralmente aceptable; los espermatozoides por parte del hombre y del óvulo por parte de la mujer, que se han de dar y aceptar recíprocamente.

b) Para JP II el acto matrimonial incrementa el amor conyugal:

- Es preciso puntualizar esta afirmación que se deduce de los fines del acto conyugal: no se acrecienta todo tipo de amor, sino preferente-

${ }^{6}$ LÓPEZ GONZÁlez R., Relevancia jurídica del amor conyugal en el matrimonio canónico. Tesis doctoral. Univ. Rey Juan Carlos. Madrid 2017. http://hdl.handle.net/10115/148 48, 2017. 
mente el amor sentimiento, de concupiscencia, definido como el querer para sí cosas que son deleitables o perfeccionan la vida personal. Es el amor a una persona concreta en tanto es fuente de satisfacciones y placeres; un tipo de amor egoísta, posesivo, no extensivo a otras personas, que se marchita hasta desaparecer cuando la persona amada (mejor dicho, querida) deja de agradar.

- En el coito esponsal suelen desencadenarse vivas reacciones afectivas; los esposos en el fondo de su ser agradecen disponer de un tú, que da cumplida satisfacción a pulsiones de tanto poderío, y con espontaneidad lo expresan con palabra y gestos de inigualable cariño. Pero no hay que confundirse, tales manifestaciones de amor son efecto, no causa. El sentimiento amoroso en el acto sexual surge a consecuencia del placer que se recibe; no es el amor lo que conduce y sostiene el ayuntamiento carnal, salvo en determinadas ocasiones, y por parte de la mujer.

- En ocasiones las relaciones sexuales no ayudan a la armonía conyugal, pues, como afirma Carlos Yela ${ }^{7}$. la realidad muestra la frecuencia de desamores a causa de unas relaciones sexuales desajustadas, por diferencias en la apetencia sexual, insatisfacciones en los apareamientos, frustraciones en la cópula, y otros fútiles detalles sobrevalorados. Por otra parte, no son las relaciones sexuales las únicas fuentes de amor en el matrimonio, pues tanta importancia o más tienen las interacciones de pareja, cuando se evita todo lo que resulte espinoso en la convivencia y se cultiva todo lo que une.

- No siempre es manifiesto el amor en el acto sexual. No son excepcionales los matrimonios que, amándose mucho, a la hora de practicar el sexo lo hacen como si no se amaran, porque cada uno va a su aire y se despreocupa del otro. Por ejemplo, el varón con la intención de mantenerse en la "fase de meseta" el mayor tiempo posible y la mujer con el ansia del orgasmo, para no sentirse inferior a otras mujeres. Aún hay casos peores, en matrimonios bien avenidos, que practican el sexo con palabras soeces e insultantes que les resultan excitantes para conseguir una plena y placentera resolución final.

c) El amor no cuenta en absoluto para una buena realización sexual, según estudios en laboratorio iniciados a mediados del siglo pasado:

\footnotetext{
7 Yela, C., El amor desde la psicología social, Ed. Pirámide, Madrid 2000, p. 156-7.
} 
- Estas investigaciones sexológicas estudian el acto sexual humano desconectado de toda relación afectiva interpersonal, igual que podría estudiarse la segregación del jugo gástrico en el hombre o en un animal, y muestran abiertamente el proceso sexual desde el inicio hasta el final en su completa organicidad. Inicialmente la sexualidad humana en su faceta genital fue estudiada en laboratorio por el ginecólogo William Masters y su ayudante la socióloga Virginia Johnson ${ }^{8}$, norteamericanos los dos, unidos en matrimonio después de unos años trabajando juntos y divorciados finalmente. Esta pareja de investigadores describieron en todo ciclo sexual cuatro fases: excitación, altiplano (meseta), orgasmo y resolución. La fase de excitación está alimentada de visiones o fantasías "eróticas” y otros variados estímulos; se manifiesta en el cuerpo con los cambios obvios y en el psiquismo con un estado de tensión placentero que pide más y más placer, y a más placer más tensión. La siguiente fase denominada altiplano o de meseta, la excitación se mantiene tras la penetración. La tercera fase orgásmica en la que la excitación llega a su punto de máxima intensidad o clímax, tiene lugar la eyaculación o emisión del líquido seminal en el hombre y el desprendimiento del tapón cervical en la mujer. En la fase de resolución se produce la regresión de los genitales al estado inicial. Las cuatro fases descritas por Masters y Johnson como "respuesta sexual humana", se reproduce de forma idéntica en todas las parejas, sin distinciones de ninguna clase.

- Años después de los estudios de Masters y Johnson la sexóloga Helen Singer Kaplan ${ }^{9}$ modificó este esquema, al establecer el modelo trifásico de respuesta sexual humana, con una primera fase de deseo, una segunda de excitación y una tercera de orgasmo. Este modelo trifásico está vigente en la actualidad y es seguido por muchas clínicas sexológicas. Tres fases universales para todas las parejas, que han de darse para que el acto sexual se consume. Fase de deseo: son momentos en los que igual el hombre como la mujer, pero más acusado en el primero, sienten la necesidad de la actividad sexual. Hay ganas de unión carnal, bajo la influencia de factores orgánicos (hormonas, algunos neuropéptidos, feromonas, es-

${ }^{8}$ Masters W. y Johnson V., Respuesta sexual humana, Intermédica, Buenos Aires 1976, p. 2-8.

${ }_{9}$ KaPlan, H.S, Manual ilustrado de terapia sexual, Ed. Random House, Barcelona 2006, pp. 12-15. 
tímulos visuales o imaginativos, olores corporales, etc.). Se trata de impulsos de carácter instintivo. Pero, estos impulsos tienen también un filtro, que a modo de motivación psicológica permite o no su satisfacción. Nadie se abandona a ellos sin más; es preciso que los afectos, conveniencia, consecuencias derivadas, entre otras consideraciones, den su aprobación o no.

- El estudio de personas que se reconocen como asexuales, hombres y mujeres que se definen por carecer de atracción sexual hacia ambos sexos, permite añadir un elemento más al modelo trifásico de Kaplan, el factor A (factor atracción) de Mora ${ }^{10}$, que al igual que los anteriores está presente en toda realización sexual humana, pero, marca su diferencia con ellos al manifestarse también con independencia a cualquier práctica sexual. Afirmar que una mujer concreta "gusta" a un hombre determinado o viceversa, es una manifestación de la sexualidad humana, ajena a la genitalidad y propia de la naturaleza psico-física sexuada del ser humano.

- Se observa que cuando no existe atracción erótica entre los sexos, por mucho amor que exista en la pareja no habrá ayuntamiento carnal. Si lo hay será con sacrificio, generalmente de la mujer, y no será un coito plenamente satisfactorio para ninguno de los dos. El amor por sí solo no tiene capacidad para la unión carnal; se puede expresar de mil formas, con abrazos, palabras, besos, atenciones, múltiples cuidados... pero es insustancial para el coito, que precisa de estos elementos: deseo, atracción erótica, excitación y unos genitales funcionales.

d) Lo que cuenta es la fuerza de las pulsiones sexuales:

- Sigmund Freud fue el psiquiatra que estudió por primera vez la sexualidad humana de forma global y estableció hace un siglo múltiples conceptos englobados todos ellos en su teoría psicoanalítica, entre ellos el de la libido ${ }^{11}$-aquella fuerza en que se manifiesta el instinto sexual- que indica la fuerza o energía cuantitativamente variable que se traduce en actos sexuales o se transforma en actividades culturales.

${ }^{10}$ Mora, J. Ma y Mora, Ma P., "Una mejor comprensión de la sexualidad humana a través del estudio de la asexualidad”, Rev Asoc. Esp. Neurops. Vol 40, nº 138. Jul-Dic. 2020. p. 115-135.

${ }^{11}$ Freud S., Introducción al Psicoanálisis. Obras completas, Vol. II, Biblioteca Nueva, Madrid 1968, p. 312. 
- Sin necesidad de aceptar los principios del Psicoanálisis, que al fin y al cabo no deja de ser una teoría muy bien argumentada y con base en datos clínicos, cualquier psicólogo sabe que la libido o energía sexual pugna por su satisfacción frente a las fuerzas represoras que actúan como muro de contención. El hombre y la mujer acuden al coito por una pulsión, empujados, arrastrados por tendencias, insertas en su naturaleza de seres humanos. Por supuesto, no se puede hablar de instinto en términos zoológicos, puesto que el hombre tiene capacidad de reflexión y libertad y en consecuencia puede actuar o no según determine su voluntad; no es una fuerza ciega que indefectiblemente se traduzca en actos. Pero, eso no es óbice para que el ser humano opte en muchísimas ocasiones por aceptar lo que se le presenta como apetecible.

- No hay por qué hablar de "donación" mutua de los esposos interpretada como manifestación de amor, porque lo que se produce es la confluencia de dos voluntades que se necesitan recíprocamente para satisfacer imperiosas necesidades eróticas: el ansia de posesión y goce en el hombre y el ansia de verse poseída en la mujer. Es un acto erótico, no de amor altruista. En el confortable estado nupcial, los esposos sin miedos ni represiones, salvo en casos de psicopatología, dan rienda suelta a sus pulsiones propias de la libido.

- Resulta evidente que el acto sexual que dispone de un marcado componente fisiológico, incluidos la emisión de semen y el desprendimiento del tapón cervical, es ajeno a los cometidos propios de las estructuras superiores de la personalidad, concretamente al amor, sea considerado como sentimiento o como dictado de la voluntad. Se comprende que la función sexual "esté situada", para muchos psicólogos, en un nivel inferior de la personalidad como una necesidad, junto al hambre, sed, sueño y descanso.

En resumen: dentro del marco matrimonial el verdadero amor con presencia palmaria y principal en el acto sexual surge tan solo accidentalmente, no constituye su esencia, falta en muchísimas ocasiones y no por eso el coito deja de ser efectivo en el placer y en el fin procreativo. El amor, el cariño y demás afectos, cuando surgen en los actos sexuales el papel que juegan dista mucho de ser determinante, por ello es inapropiado concederles importancia y menos aún levantar toda una estructura ideológica sobre esta base. 


\section{OTROS ASPECTOS DEL ACTO CONYUGAL EN JP II}

\subsection{El coito matrimonial es un acto honorable}

Al ser considerada la cópula matrimonial una expresión de amor, la sexualidad conyugal sobrepasa su dimensión biológica-corporal-instintiva y se presenta con apariencia espiritual muy moderna. Juan Pablo II lleva a cabo esta exposición al reflexionar sobre las secuencias del Génesis sobre la creación del hombre a imagen y semejanza de Dios, que es amor y le confiere a la pareja primigenia la capacidad para amar "no solo a través de la propia humanidad, sino también a través de la comunión de las personas que el varón y la mujer forman desde el comienzo"12. De esta forma asume la expresión del Concilio: "Por ello los actos con los que los esposos se unen íntima y castamente entre sí son honestos y dignos" (GS 49). Es evidente su voluntad de presentar la sexualidad humana de forma positiva y borrar la antigua imagen de algo sucio, indecente, pecaminoso, mantenida secularmente por la Iglesia, bajo variados influjos culturales de los que posiblemente fue contaminada.

La honestidad del acto conyugal en cuanto es permitido para la procreación está fuera de toda discusión, y afirmar su dignidad significa que es un acto establecido por Dios, por cuya razón nada rechazable puede encubrir. Honestidad y dignidad otorgadas a la unión íntima de los esposos supuso un paso adelante en la restitución de la honorabilidad de la unión íntima conyugal iniciada por Pío XII que reconoció el placer legítimo del acto conyugal ${ }^{13}$ y declaró: "(vosotros) tenéis el legítimo anhelo de veros circundados por una gloriosa corona de hijos, fruto de vuestra unión. Pero también el estado matrimonial querido por Dios para el común de los hombres, puede y debe tener su pureza sin mancha" ${ }^{14}$.

El coito conyugal con más razón aún ha de ser considerado honesto y digno si está etiquetado de ser una expresión de amor. Pero, se echa en falta que Wojtyla al referirse al acto conyugal no mencionara la moderación que es obligada observar en su realización, pues no se puede olvidar

12 Juan Pablo II, Varón y mujer. Teología del cuerpo, Ed. Palabra, Madrid 1996, p. 73.

${ }^{13}$ Pío XII., Encíclica «Sacra Virginitas», 1954, www.corazones.org

${ }^{14}$ Pío XII. "Discursos a los recién casados entre los años 1939 y 1943". Alocución "La castidad conyugal", del 6 de diciembre de 1939. Consultado: 26-4-2021. Disponible en: http://www.catolicosalerta.com.ar > la-familia-cristiana. 
que la lujuria también se da en las relaciones conyugales y no todos los actos por el simple hecho de realizarse dentro del ámbito matrimonial están exentos de ella. Prueba de vicio es la frecuencia de adulterios que surgen cuando, agotados los estímulos excitantes del lecho conyugal, se buscan nuevos estímulos extramatrimoniales. También contradice esta supuesta honorabilidad del acto matrimonial el hecho comprobado de "sexo a todas horas", hoy llamado "adicción al sexo", en la que caen algunos matrimonios. Una patología comparable a otras adicciones que aparece en ambos sexos, en solteros y en casados. Esta adicción fue descrita con detalle por primera vez por P. Carnes ${ }^{15}$, y de cuya divulgación se han encargado famosos actores de cine en un noble afán de prevenirla. Por esto, a muchos les resulta difícil comprender que el coito realizado por quienes no están casados sea expresión del ansia de placer o lujuria y dentro del matrimonio manifestación de mutuo afecto.

Poder fijar el límite entre el acto conyugal honorable y el que no lo es resulta una tarea interesante y desde luego requiere otro estudio. Por ahora baste decir, primero: que el vínculo matrimonial solo parcialmente puede ser criterio diferenciador, y segundo: el acto sexual realizado ante la necesidad de unión hombre-mujer que anula el sentimiento íntimo de soledad, permite acercarnos a reconocer la dignidad del acto.

Todo lo dicho no contradice la existencia de notables diferencias, en cuanto a dignidad entre actos sexuales realizados en mutua exclusividad dentro de la vida matrimonial y los extramaritales. Es muy diferente el coito marital en el ámbito entrañable del ambiente familiar, una comunidad de amor dispuesta para la procreación y educación de la prole, que fuera del matrimonio, donde, tantas veces, se observa con notable incongruencia la práctica de actos íntimos entre quienes no tienen siquiera intimidad, y cuya finalidad única es el placer. Otro tanto ocurre con las relaciones sexuales practicadas por adolescentes, apenas alcanzada la pubertad, que, con la mayor ligereza y frivolidad, a modo lúdico, envilecen una función encaminada a perpetuar la vida humana. Verdaderamente, existe una clara línea divisoria entre los actos conyugales y todos los demás.

15 CARnes, P. J., Out of the shadows, understanding sexual addictions, Minneapolis, CompCare Publishers, 1983. 


\subsection{Los actos sexuales han de ser realizados de manera humana}

Wojtyla también hace suyas estas palabras de Gaudium et Spes, que años después incorporaría al nuevo Derecho Canónico de 1983: "Ejecutados (los actos sexuales) de manera verdaderamente humana, significan y favorecen el don recíproco, con el que se enriquecen mutuamente en un clima de gozosa gratitud" (GS 49). Posteriormente, siendo ya Papa repetirá y aclarará su sentido en la Familiaris Consortio (FC), lo que confirma la autoría común de ambos documentos, o al menos una parte de la Gaudium et Spes:

La sexualidad, mediante la cual el hombre y la mujer se dan uno a otro con los actos propios y exclusivos de los esposos, no es algo exclusivamente biológico, sino que afecta al núcleo íntimo de la persona humana en cuanto tal. Ella se realiza de modo verdaderamente humano, solamente cuando es parte integral del amor con el que el hombre y la mujer se comprometen totalmente entre sí hasta la muerte (FC 11).

No es baladí que Juan Pablo II afirmara que el acto sexual se ha de realizar de "modo humano", pues este requerimiento ha tenido su traducción en el Derecho Canónico de 1983 (que modificó el de 1917, bajo su pontificado) y en el canon 1061 se establece este requisito para la consumación del matrimonio:

El matrimonio válido entre bautizados se llama solo rato, si no ha sido consumado; rato y consumado, si los cónyuges han realizado de modo humano el acto conyugal apto de por sí para engendrar la prole, al que el matrimonio se ordena por su misma naturaleza y mediante el cual los cónyuges se hacen una sola carne.

Los actos matrimoniales que de verdad hayan de ser considerados humanos son todos aquellos que son eficaces para procrear, incluyendo también a esos que en su realización lo serían, si una causa biológica natural no lo impidiera. Desde siempre se han desestimado los realizados de forma que el semen no entra en la vagina, pero, con la innovación "personalista" de Juan Pablo II, un segundo requisito se añade, por lo que Cormak Burke afirma: "La implicación principal sería que la relación física conyugal no se lleva a cabo humano modo tan solo porque esté abierta a la procreación" ${ }^{16}$. La interpretación de esta exigencia no ofrece dificultad

${ }^{16}$ BuRKe, C, "La concupiscencia y el amor conyugal: un análisis más profundo". Consultado el 12/5/2021. Disponible en.www.cormacburke.or.ke 
si el acto ha sido realizado con violencia, sin libertad o sin conciencia, pero para los peritajes judiciales representa un serio problema en todos los demás casos, en los que participa en gran medida el subjetivismo de las dos partes actoras. Se trata de un verdadero problema que algunos teólogos han querido resolver apelando a la delicadeza utilizada; si el acto ha estado presidido por un interés que se olvida de sí mismo y busca satisfacer al cónyuge; si se ha atendido a los gustos y preferencias de la otra parte... Para Wojtyla la ternura manifestada en el acto sexual supone una clara manifestación de amor y hace que el acto se haya realizado de forma humana:

La ternura proviene de la afectividad y, en el caso que nos interesa de esta reacción ante el ser humano de sexo diferente, que la caracteriza. No expresa la concupiscencia sino más bien la benevolencia y abnegado afecto $^{17}$.

Se recurre a los dos tipos clásicos de amor de los que habló Tomás de Aquino (concupiscente y benevolente), e importa que en el acto sexual estén presentes los dos para que sea un acto específicamente humano. Esta misma idea la expone Cormac Burke ${ }^{18}$ al interpretar que el acto sexual es humano cuando se practica atendiendo al otro: se expresa humanamente no solo en el dar y recibir placer sino aún más esencialmente en el cuidado, respeto, ternura y reverencia que acompañan el acto físico.

Yves Semen, filosofo especializado en la "teología del cuerpo" afirma al respecto que cada uno de los esposos ha de observar en el otro el ritmo de progresión en el placer, la especial sensibilidad, sus gustos y preferencias: que cada uno esté atento al otro más que a sí mismo y dé pruebas de una verdadera actitud altruista en la gestión del acto sexual ${ }^{19}$.

En realidad, la forma de llevar a cabo la cópula desde el cortejo hasta el pos-coito forma parte del manual del buen amante, en el que se incluye al don juan y al casanova. Amantes que saben cómo tratar a las damas en esos trances, aunque no busquen, egoístamente, otra finalidad que su propio beneficio. Lamentablemente, hay maridos que aman a sus esposas

${ }^{17}$ Wojtyla, K., Amor y responsabilidad, cit, p. 226.

18 Burke, C. cit.

${ }^{19}$ Semen, Y, La sexualidad según Juan Pablo II, $4^{\mathrm{a}}$ ed., Desclee de Brouwer, Bilbao 2005, p. 169. 
pero se muestran torpes e ineptos en esos momentos, pero no por eso sus actos se podrían tachar de inhumanos. Esto ocurría especialmente a principios del pasado siglo y es de suponer que de aquí hacia atrás durante un tiempo indefinido. El ginecólogo holandés Van de Velde (1873-1937) tuvo conocimiento de desastrosas relaciones sexuales en matrimonios muy unidos en el amor y para corregir este auténtico mal social escribió Matrimonio ideal, en el que enseñaba, especialmente al varón cómo debía iniciar y proseguir una relación enfocada al coito. El mencionado libro, que tuvo un gran éxito de ventas, actualmente es imposible encontrarlo pero el sexólogo Edward M. Brecher ${ }^{20}$ tuvo ocasión de leerlo y nos ha transmitido lo más importante de él. Dice que en el "preludio" del ceremonial erótico el marido debe iniciar el cortejo con frases cariñosas, miradas, gestos, acercamiento físico y otros muchos detalles que juegan un importante papel, imprescindibles para encarrilar adecuadamente el proceso. Sobre todo, se ha de hablar de amor con frases cargadas de romanticismo. En definitiva, enseña cómo ha de conducirse el varón para que el acto concluya con plena satisfacción de las dos partes. Desde entonces, publicaciones encaminadas al mismo fin se han divulgado especialmente por los países occidentales. Pío XII reconocía, en tiempos de su pontificado (1939-1958) que los matrimonios debían poseer "las técnicas adecuadas":

Artículos, capítulos, libros enteros, conferencias, especialmente sobre la «técnica del amor», están dedicados a difundir estas ideas, a ilustrarlas con advertencias a los recién casados como guía del matrimonio para que no dejen pasar por tontería o por mal entendido pudor o por infundado escrúpulo lo que Dios, que ha creado también las inclinaciones naturales, les ofrece ${ }^{21}$.

En el acto sexual, no porque exista amor sino por un mínimo conocimiento psicológico, la presencia del tú será tenida en cuenta, y aunque eso no significa que sea un acto esencialmente amoroso puede cumplir el segundo requisito de ser un acto realizado de forma humana.

${ }^{20}$ BRECHER, E. M. Investigadores del sexo, México DF, Ed. Grijalbo, 1973, pp. 133 156.

${ }^{21}$ Pío XII. "Discurso del Santo Padre al congreso de la unión católica italiana de comadronas con la colaboración de la federación nacional de colegios de comadronas católicas", lunes 29 de octubre de 1951. 
Juan Pablo II, autor responsable de dos tercios del Magisterio actualizado de la Iglesia Católica sobre el matrimonio y la familia, impuso la doctrina sobre el acto conyugal orientado según su fin a incrementar el amor conyugal y a llamar (actual o potencialmente) nuevas vidas. Unas ideas muy divulgadas que han tenido gran aceptación, sobre todo en los círculos eclesiales católicos.

\subsection{Los esposos se aman con el cuerpo}

En el capítulo sobre la dignidad de la persona quedó plasmada la relevancia que el Concilio le dio al cuerpo humano: "no debe, por tanto, despreciar la vida corporal, sino que, por el contrario, debe tener por bueno y honrar a su propio cuerpo" (GS, 14). El cuerpo humano, secularmente relegado a un papel de inferior categoría, se revalorizó y más concretamente Wojtyla lo hizo en sus conocidas enseñanzas comprendidas en lo que llamó "teología del cuerpo," que viene a ser una antropología propia centrada en la naturaleza del hombre, en el amor y la sexualidad. En "Varón y mujer. Teología del cuerpo" hay profusas referencias al cuerpo humano, sobre todo en sus 92 reflexiones sobre los primeros capítulos del Génesis, tanto del texto yahvista, el más antiguo (Génesis 2), como del elohísta (Génesis 1). "El cuerpo revela el hombre"22, expresión similar a "el cuerpo expresa la persona (...) revela al alma viviente" ${ }^{23}$, frases que dan constancia de la pertenencia del hombre al mundo material donde está implantado y ha de relacionarse con el resto de los seres vivientes. Así, al referirse a la creación del hombre por Dios reproduce el pasaje del Génesis: "Formó Jahveh-Dios al hombre del polvo de la tierra y le inspiró en el rostro aliento de vida" (Génesis 2,7).

Para alcanzar el concepto de amarse los esposos con el cuerpo, Wojtyla previamente ha de recordar una verdad inapelable: la unión íntima entre el alma y el cuerpo. Por eso en "Varón y Mujer" recuerda que la unión alma y cuerpo, no es accidental, al ser dos dimensiones constitutivas de una unidad que es el hombre. En el cuerpo, informado por el alma inmortal, de acuerdo con la filosofía aristotélica, se expresan los más espirituales sentimientos, tal es el amor entre los esposos cuando se unen al

\footnotetext{
22 JUAN PABLO II, Varón y mujer. cit. p. 75.

${ }^{23}$ Ibid. p. 103
} 
copular: "Es un error reducir la persona humana a una libertad espiritual, puramente formal. Esta reducción ignora el significado moral del cuerpo y de sus comportamientos" 24 .

El concepto llamativo de "amar con el cuerpo" ennoblece la parte material del hombre, en tanto se vincula con un sentimiento propio de la dimensión espiritual humana. Wojtyla indica que el cuerpo humano en la relación sexual entre esposos se da al otro, es decir el cuerpo es prenda de amor. Con este significado Wojtyla usa amar como un verbo de acción, no como un verbo de sentimientos; amar es empleado en vez de copular que es acción ejercitada con los genitales.

Para Wojtyla el cuerpo también participa del amor que expresa el acto conyugal. De aquí la divulgada frase de "amar con el cuerpo". que es rebatible porque ya está dicho que el acto conyugal no es una expresión de amor. Por eso, no hay razón para hablar de "amar con el cuerpo" como en su día enseñó Karol Wojtyla. No obstante, la expresión tan divulgada implica ingenio, pues el alcance de su argumentación era concluir que el acto sexual será inmoral si el amor no es pleno y no exige la inclusión de los gametos:

La donación física total sería un engaño si no fuese signo y fruto de una donación en la que está presente toda la persona, incluso en su dimensión temporal; si la persona se reservase algo o la posibilidad de decidir de otra manera en orden al futuro, ya no se donaría totalmente ${ }^{25}$.

Por lo tanto ha de excluirse todo artificio encaminado a impedir la procreación, sea cual sea el tipo utilizado, que supondría un menoscabo al amor que se manifiesta. De acuerdo con el significado unitivo y procreativo de la Humanae Vitae, JP II afirma con lógica que el hijo ha de ser fruto y expresión del acto conyugal: la procreación de una nueva persona, en la que el varón y la mujer colaboran con el poder del Creador, deberá ser el fruto y el signo de la mutua donación personal de los esposos, de su amor y de su fidelidad. JP II alcanza así una conclusión mantenida desde siempre por la Iglesia Católica; en otras ocasiones expresada de una forma

${ }^{24}$ JuAn PABlo II, Encíclica "Veritatis Splendor”, 49, Roma, Libreria Editrice Vaticana, 1993.

25 JuAn Pablo II, Encíclica "Familiaris Consortio", 1981, Segunda parte, 11, Roma, Libreria Editrice Vaticana, 1981. 
más simple, no menos clara y sin posibilidad de discusión, tal afirmaba Pío XI:

Eleva (el Papa) solemne su voz por Nuestros labios y una vez más promulga que cualquier uso del matrimonio, en el que maliciosamente quede el acto destituido de su propia y natural virtud procreativa, va contra la ley de Dios y contra la ley natural, y los que tal cometen, se hacen culpables de un grave delito $(26)^{26}$.

\section{Conclusiones}

El interés de JP II por la defensa del matrimonio y la familia se plasmó en la creación de los Institutos Pontificios Teológicos que llevan su nombre, orientados a un conocimiento especializado en temas relacionados con estas instituciones básicas de la sociedad. Instituciones ciertamente amenazadas por los nuevos movimientos ideológicos surgidos a finales del XIX y de progresión llamativa. Importa que las enseñanzas impartidas en estos centros, cuya creación fue un gran acierto, se purifiquen de toda elucubración subjetiva y sirvan para la mejor edificación de toda persona.

San Agustín, obispo de Hipona, mantuvo que el acto sexual matrimonial entraña un mal, permitido en cuanto encierra el bien de la procreación ${ }^{27}$. Con tan elemental idea cualquier cristiano, durante siglos, ha comprendido que del acto matrimonial no se podía excluir su potencia procreadora. Ahora bien, si dicho acto se engalana con la nobleza del sentimiento amoroso habría que preguntarse si el amor no se estará utilizando desde hace décadas como coartada para realizar todo tipo de actos sexuales, ¿quién se culpará de realizarlo fuera del matrimonio? ¿Por qué razón -argüirán algunos teólogos- prohibir las relaciones entre personas de un mismo sexo?

Wojtyla quiso cambiar para bien una visión negativa de la sexualidad humana por otra positiva, de acuerdo con el espíritu conciliar. Enseñó que los actos sexuales son un medio que "perfecciona" el amor conyugal. Ade-

${ }^{26}$ Pío XI, Encíclica “Casti Connubii”, 21, Roma. Libreria Editrice Vaticana, 1930.

27 Agustín, SAn, El matrimonio y la concupiscencia, Libro Primero, IV. 8, Consultado: 31-3-2020. Disponible en: https://www.augustinus.it/spagnolo/nozze_concupiscenza/index2. htm. 
más, atento al Génesis, interpretó que la sexualidad tras la caída de nuestros primeros padres, sufrió una degradación y el don mutuo y recíproco de sí fue sustituido por la cosificación del otro, convertido en objeto de placer $^{28}$. Hacer del acto sexual una expresión de amor es, de cierta manera, una forma de recuperar la "inocencia primigenia". Con tan positivas perspectivas a los matrimonios les ofrece, o más bien, les invita a que prodiguen sus prácticas sexuales, pero con una "entrega total", que viene a ser una advertencia de la obligatoriedad de que sean actos abiertos a la vida, so pena de caer en grave deshonestidad. La intención del Papa era buena, pero a la postre venía a azuzar el duro dilema que hoy soportan los fieles católicos que han de elegir entre la continencia o una fecundidad ilimitada.

A todo matrimonio que por cualquier medio impida la procreación en el acto conyugal habrá que aclararle, siguiendo la doctrina de JP II, que practica el sexo sin amor, que no se ama o no se ama lo suficiente. La conclusión de este razonamiento no puede por menos que irritar o encolerizar a todos aquellos, hombres y mujeres, que viviendo maritalmente en feliz concordia sienten la acusación de no amarse "totalmente" como el Papa exigía.

La revalorización del cuerpo cosa que ya se patentiza con el simple enunciado de "teología del cuerpo", ha podido interpretarse como una aceptación de actividades muy vinculadas a él, como es sin duda la sexual. Y no solo eso, muchos se preguntarán si el cuerpo no es merecedor de otros muy variados placeres, como pueden ser la buena comida y bebida, el confort, el regalo, un hedonismo esplendoroso en definitiva y también una restitución de la materialidad mundana.

${ }^{28}$ JUAn PABLO II, Varón y mujer, cit., pp. 113-129. 